\title{
CASOS DE HIPERTENSÃO ARTERIAL NO ESTADO DO AMAPÁ ENTRE OS ANOS DE 2006 E 2012
}

\section{ARTIGO ORIGINAL}

FEIO, Stefanie Cecilia Passinho ${ }^{1}$

FECURY, Amanda Alves ${ }^{2}$

OLIVEIRA, Euzébio ${ }^{3}$

DENDASCK, Carla Viana ${ }^{4}$

DIAS, Claudio Alberto Gellis de Mattos ${ }^{5}$

FEIO, Stefanie Cecilia Passinho. Et al. Casos de Hipertensão Arterial no Estado do Amapá entre os anos de 2006 e 2012. Revista Científica Multidisciplinar Núcleo do Conhecimento. Ano 05, Ed. 04, Vol. 04, pp. 105-115. Abril de 2020. ISSN: 2448-0959, Link de acesso: https://www.nucleodoconhecimento.com.br/saude/casos-dehipertensao-arterial, DOI: 10.32749/nucleodoconhecimento.com.br/saude/casos-dehipertensao-arterial

1 Técnico em mineração pelo Instituto de Ensino Básico, Técnico e tecnológico do Amapá (IFAP).

${ }^{2}$ Biomédica, Doutora em Doenças Topicais, Professora e pesquisadora do Curso de Medicina do Campus Macapá, Universidade Federal do Amapá (UNIFAP).

3 Biólogo, Doutor em Doenças Topicais, Professor e pesquisador do Curso de Educação Física da, Universidade Federal do Pará (UFPA).

${ }^{4}$ Teóloga, Doutora em Psicanálise, pesquisadora do Centro de Pesquisa e Estudos Avançados- CEPA.

${ }^{5}$ Biólogo, Doutor em Teoria e Pesquisa do Comportamento, Professor e pesquisador do Curso de Licenciatura em Química do Instituto de Ensino Básico, Técnico e tecnológico do Amapá (IFAP). 


\section{RESUMO}

A hipertensão arterial é a elevação fora do normal da pressão que o sangue realiza nas paredes dos vasos sanguíneos de um indivíduo. $O$ aumento da pressão arterial ocorre de forma silenciosa de modo que seus sintomas podem não ser sentidos em um primeiro momento. $O$ tratamento da hipertensão pode ser feito através de medicamentos farmacêuticos ou através de simples ações como a modificação dos hábitos diários para hábitos mais saudáveis. O objetivo desta pesquisa é mostrar o número de casos de hipertensão no estado do Amapá entre os anos de 2006 e 2012. A pesquisa foi realizada no banco de dados DATASUS (http://datasus.saude.gov.br/). O número de casos de hipertensão no Amapá no período de 2006 a 2012 oscila bastante entre os anos ocorrendo mais na capital do estado; em mulheres é maior do que em homens; na faixa dos 50 anos até os 69 anos é maior que o número de casos nas demais idades; e a maioria dos casos não tem influência de sobrepeso, sedentarismo ou tabagismo. No Amapá casos de hipertensão persistem pela falta de aderência ao tratamento ou ao tratamento incorreto, ocasionado pela falta de informação sobre a gravidade da pressão alterada para a saúde. Mulheres apresentam maior cuidado pessoal com a saúde e maior manutenção do tratamento após o diagnóstico. Doenças crônicas não transmissíveis oferecem maior risco à população com maior faixa etária. A causa efetiva dos casos de hipertensão no Amapá parecem ser o fator genético e o estresse, suplantando fatores como sobrepeso e sedentarismo. A escolaridade reduzida leva a insegurança no trabalho, aumentando o estresse e alterando a pressão sanguínea. O tabagismo não se apresenta como fator principal pois sua redução nacional foi alcançada com campanhas educacionais de jovens. Infelizmente, casos de dificuldade de acesso a saúde, diagnóstico e tratamento de pacientes hipertensos permanecem reais no interior do estado.

Palavras-chave: Hipertensão arterial, Amapá, epidemiologia.

\section{INTRODUÇÃO}

A hipertensão arterial é a elevação fora do normal da pressão que o sangue realiza nas paredes dos vasos sanguíneos de um indivíduo. O padrão considerado normal é 
de 120/80 mmHg. Valores acima ou muito abaixo desses são considerados anormais (Micheli e Bitarello, 2008).

Ela pode ser causada por fatores hereditários, quando o gene da doença é passado de pai para filho, ou por fatores considerados fatores de risco tais como tabagismo, sobrepeso, sedentarismo, sexo, faixa etária e alcoolismo (Zaitune et al., 2006).

O aumento da pressão arterial ocorre de forma silenciosa de modo que seus sintomas podem não ser sentidos em um primeiro momento. Em muitos casos quando a hipertensão já está em estágios mais avançados os sintomas poderão eventualmente ser percebidos (Monteiro et al., 2005).

Existem dois tipos de hipertensão: primaria (essencial) e secundaria (não essencial). No tipo primário a elevação da pressão possui causas desconhecidas. Esse é o tipo mais comum entre os pacientes. $O$ tipo secundário de hipertensão geralmente possui causa identificável. É causada por fatores temporários como a gravidez, o uso contínuo de medicamentos, ou por fatores crônicos como doenças renais que levam a pressão do paciente a se elevar. Esse tipo corresponde à minoria dos casos (Fonseca et al., 2009).

O tratamento da hipertensão pode ser feito através de medicamentos farmacêuticos ou através de simples ações como a modificação dos hábitos diários para hábitos mais saudáveis. $\mathrm{O}$ tratamento com medicamentos farmacêuticos é indicado onde casos possivelmente já estão afetando o indivíduo de maneiras danosas ou quando o aumento da pressão é causado por outras doenças mais graves. Para casos onde a hipertensão ainda não é grave ou para prevenção recomenda-se o uso de medicamentos naturais, a prática de exercícios físicos e cuidados com os considerados fatores de risco (Zaitune et al., 2006).

Dados da pesquisa nacional de saúde do IBGE realizada em 2013 apontavam que 1/5 da população brasileira, 31,3 milhões de pessoas, era hipertensa. No mesmo ano os dados mostravam que a hipertensão na região Sul do país acometia 22,9\% da população. No Sudeste eram $23,3 \%$ de casos; no centro-oeste $21,1 \%$; no nordeste 
19,4\%; e no norte 14,5\%. O estado do Amapá, em 2013, apresentava 13,3\% da população com hipertensão (Andrade et al., 2015).

\section{OBJETIVOS}

Analisar a porcentagem de casos de Hipertensão no estado do Amapá entre os anos de 2006 e 2012.

\section{MÉTODO}

A pesquisa foi realizada no banco de dados DATASUS (http://datasus.saude.gov.br/). Foram coletados dados nacionais de acordo com as seguintes etapas: A) Acessou-se o link datasus.gov.br, clicou-se na aba "acesso a informação", foi-se a "sistema de informação (Tabnet)", clicou-se em "Epidemiológicas e Morbidade”. Na página aberta foi-se a "Hipertensão e diabetes". Na outra página seleciona-se a opção "Hiperdia" e na caixa "abrangência geográfica" optou-se pelo estado do Amapá. Para cada estado seguiram-se os passos: Na linha, selecionou-se "Ano", na coluna "não ativa". e no conteúdo, "Hipertensão"; "Sexo"; "Faixa Etaria"; "Sobrepeso"; "Sedentarismo"; "Tabagismo"; e "Região Metropolitana". Para todas as opções do campo linha acima foram utilizados na coluna o campo "não ativa" , no conteúdo o campo "Hipertensão", e no campo "periodos disponiveis" foram coletados dados entre os anos de 2006 e 2012. A compilação dos dados foi feita dentro do aplicativo Excel, componente do pacote Office da Microsoft Corporation. A pesquisa bibliográfica foi realizada em artigos científicos, utilizando-se para busca computadores do laboratório de informática do Instituto Federal de Educação, Ciência e Tecnologia do Amapá, Campus Macapá, situado na: Rodovia BR 210 KM 3, s/n - Bairro Brasil Novo. CEP: 68.909-398, Macapá, Amapá, Brasil.

\section{RESULTADOS}

A figura 1 apresenta a porcentagem de casos de hipertensão no Amapá no período de 2006 a 2012. Os dados mostram que a quantidade de casos oscila bastante e o 
seu pico foi em 2009 , onde o número de casos aumentou $15 \%$ em relação ao ano anterior.

Figura 1 Porcentagem de casos de hipertensão no estado do Amapá no período de 2006 a 2012.

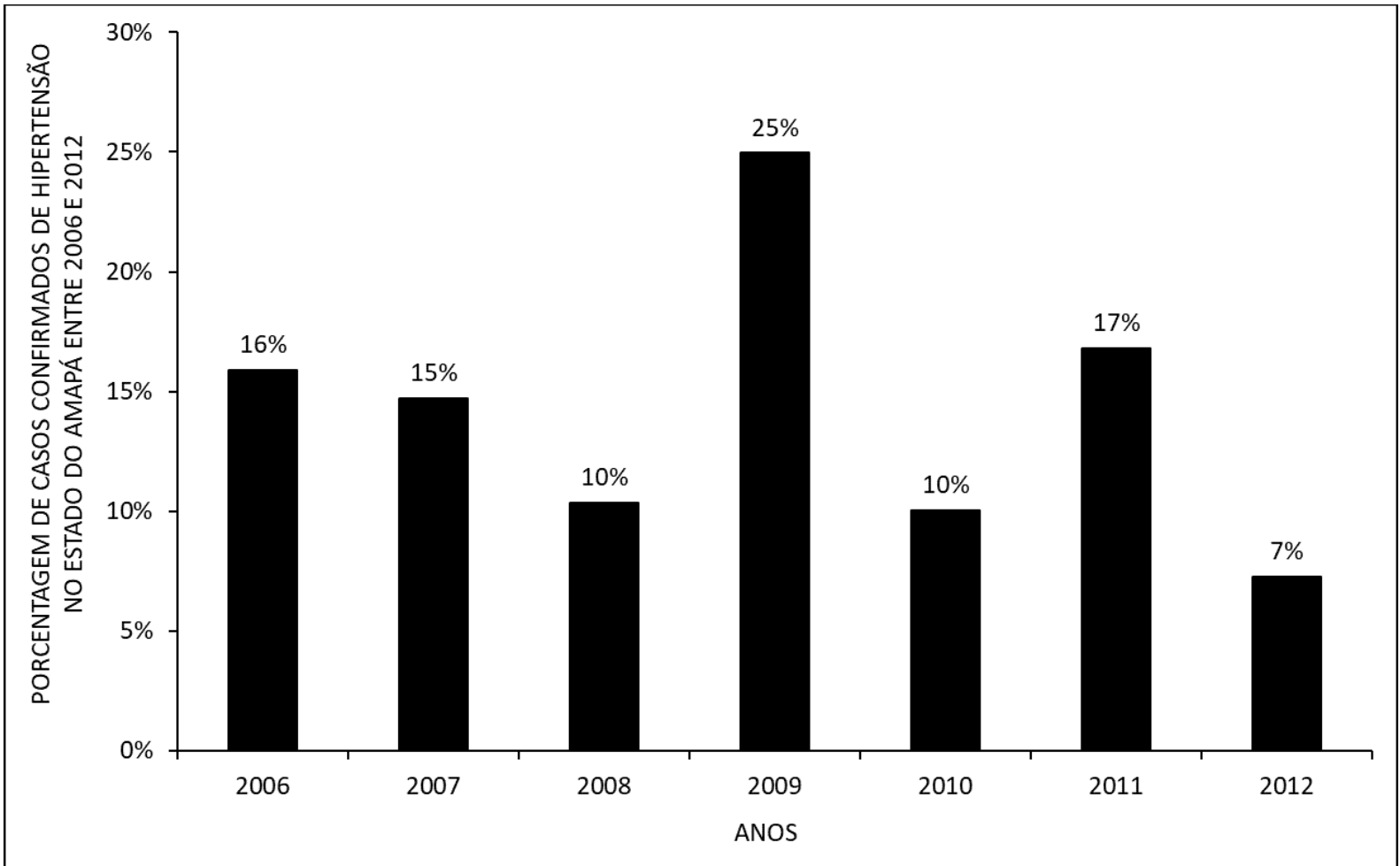

A figura 2 mostra a porcentagem de casos de hipertensão no estado do Amapá no período de 2006 a 2012 por gênero. Os dados mostram que a quantidade de casos em mulheres, no cômpito geral é de $61 \%$, e de homens $39 \%$. 
Figura 2 Número de casos de hipertensão no estado do Amapá no período de 2006 a 2012 por gênero.

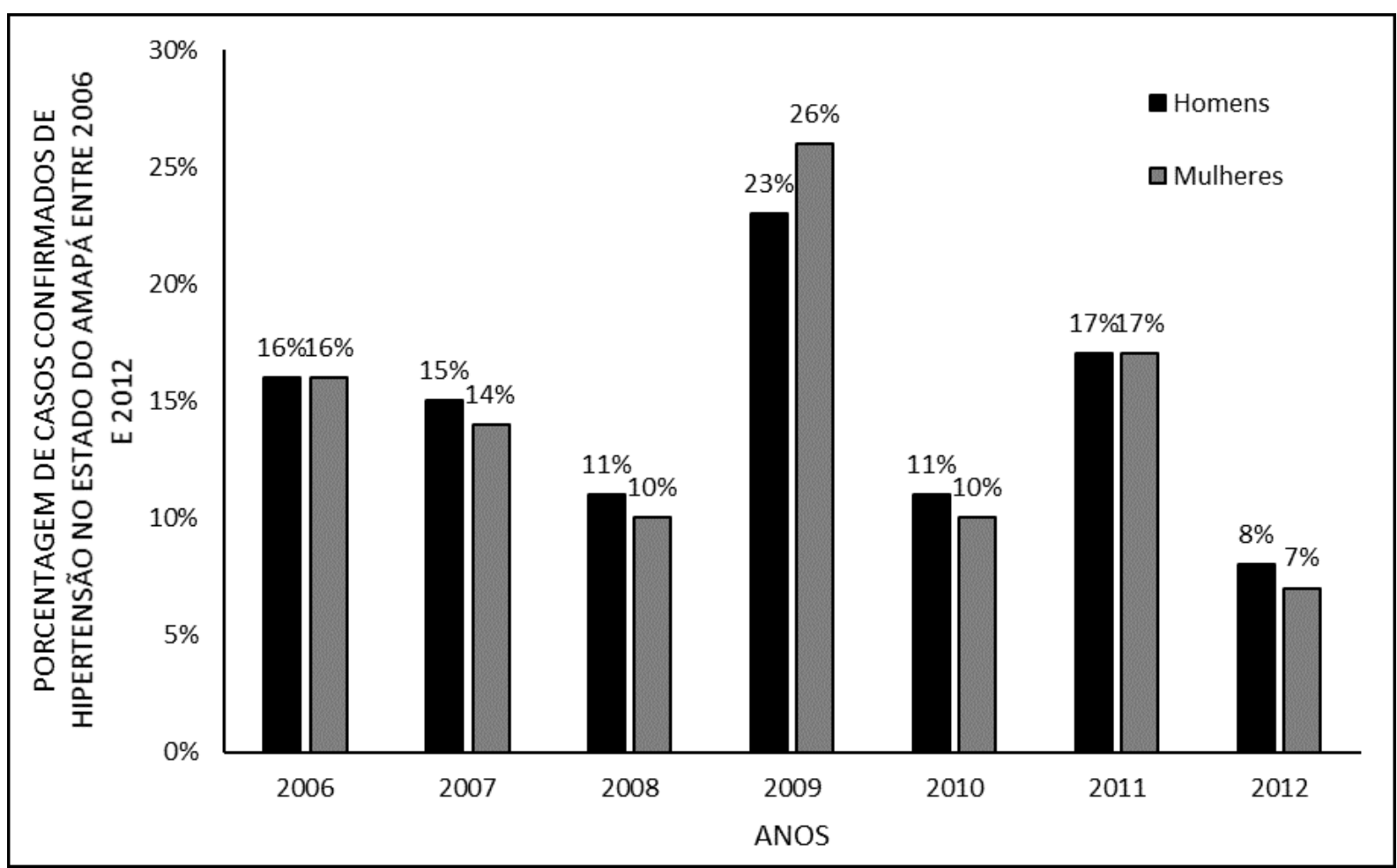

A figura 3 mostra o número de casos de hipertensão no estado do Amapá no período de 2006 a 2012 por faixa etária. Os dados mostram que o número de casos em pessoas na faixa dos 50 anos até os 69 anos é maior que o número de casos nas demais idades. 
Figura 3 Número de casos de hipertensão no estado do Amapá no período de 2006 a 2012 por faixa etária.

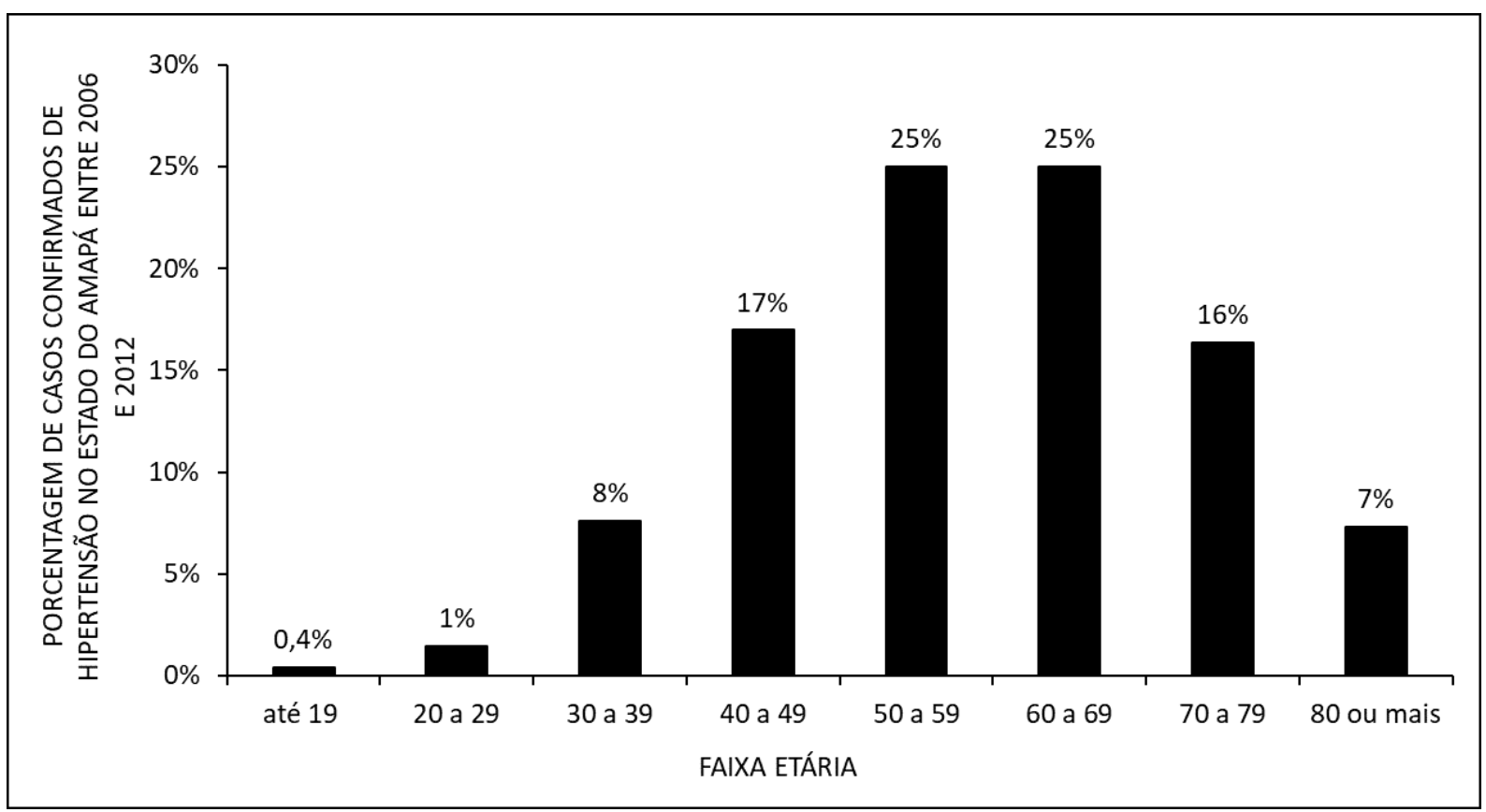

A figura 4 mostra o número de casos de hipertensão no estado do Amapá no período de 2006 a 2012 por sobrepeso. Os dados mostram que os casos de hipertensão causados por sobrepeso são aproximadamente $50 \%$ menores que os casos de hipertensão não causados por sobrepeso. 
Figura 4 Número de casos de hipertensão no estado do Amapá no período de 2006 a 2012 por sobrepeso.

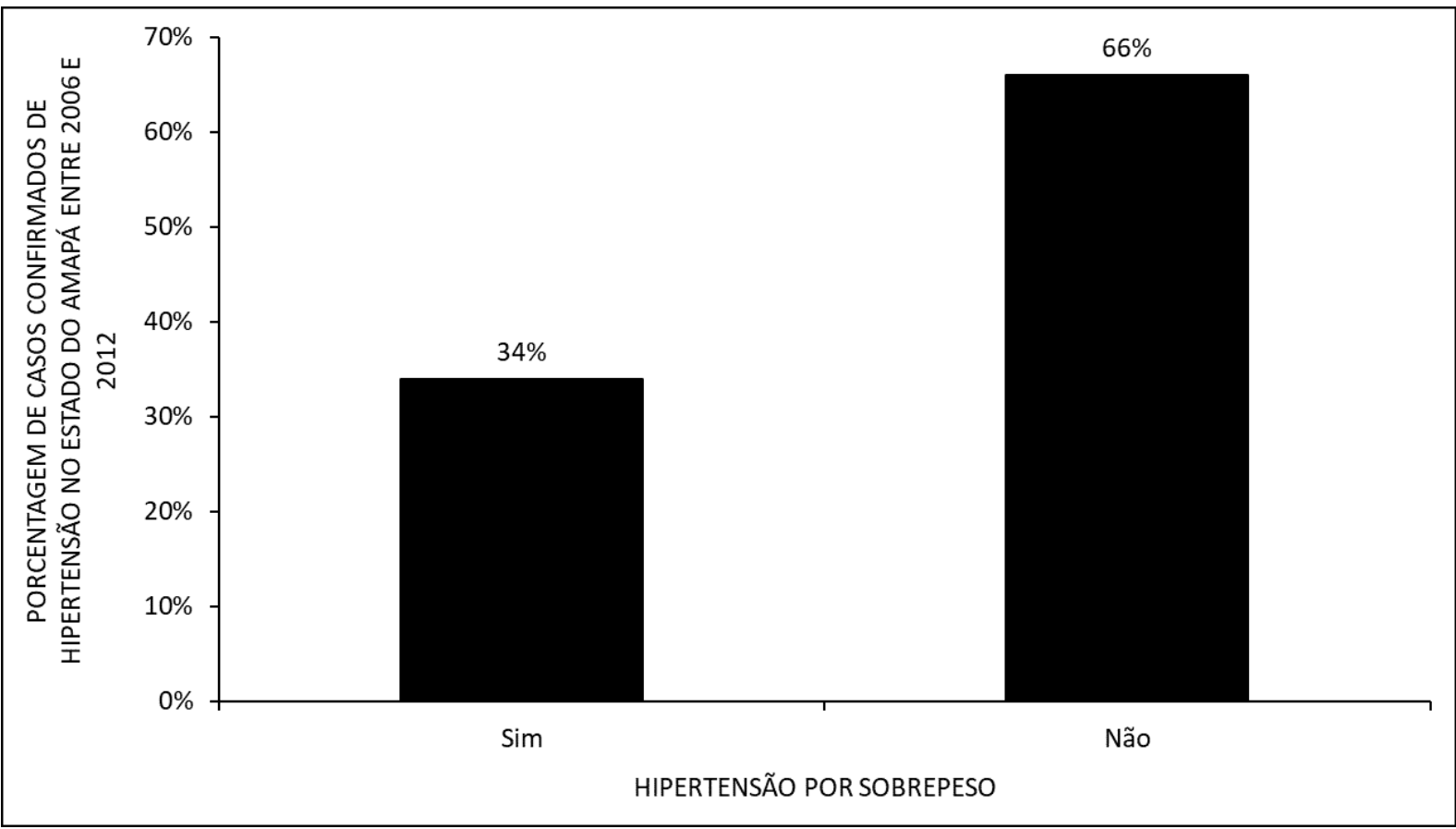

A figura 5 mostra o número de casos de hipertensão no estado do Amapá no período de 2006 a 2012 por sedentarismo. Os dados mostram que os casos de hipertensão causados por sedentarismo correspondem a aproximadamente $50 \%$ dos casos de hipertensão não causados por sedentarismo. 
Figura 5 Número de casos de hipertensão no estado do Amapá no período de 2006 a 2012 por sedentarismo.

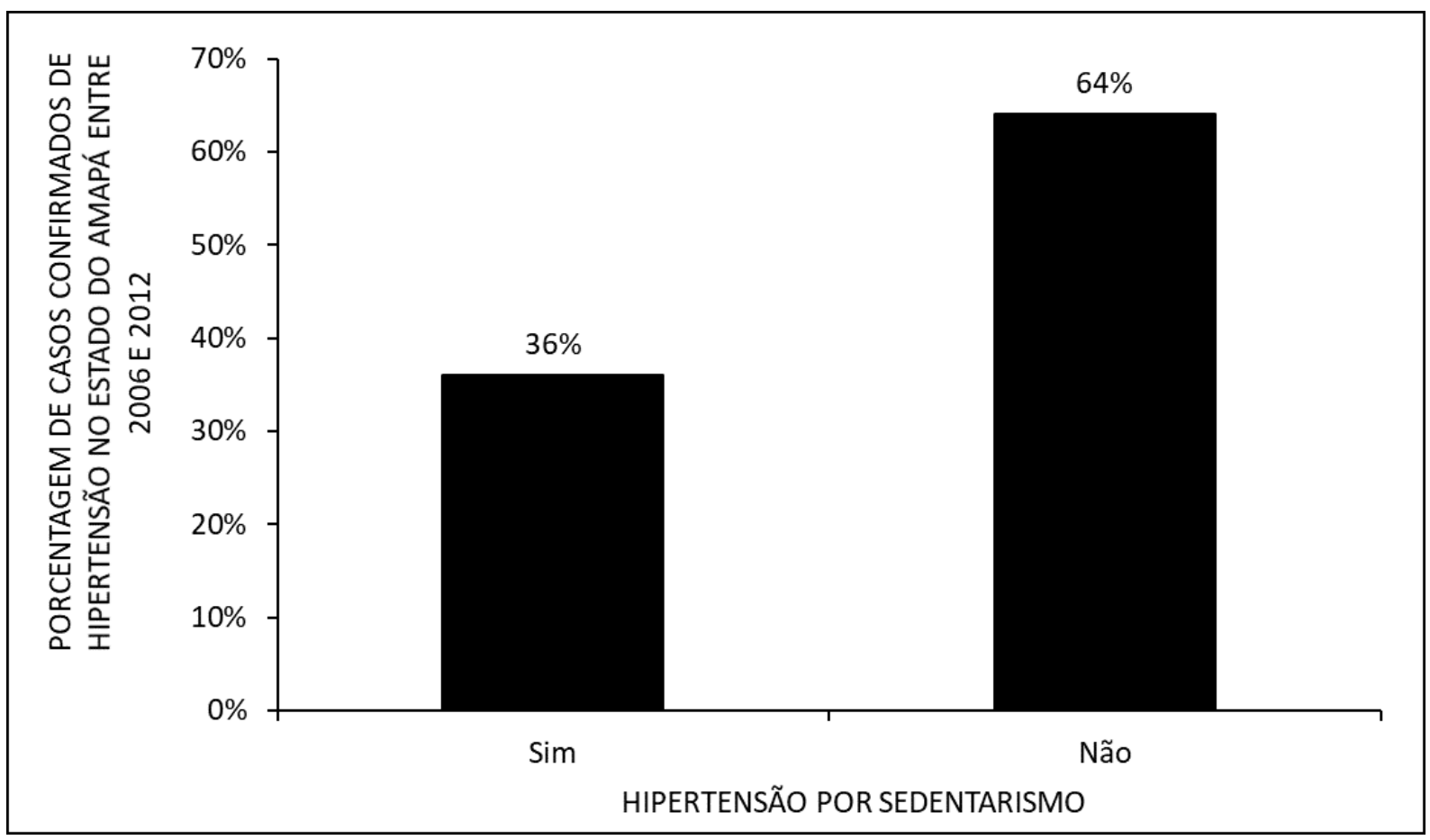

A figura 6 mostra o número de casos de hipertensão no estado do Amapá no período de 2006 a 2012 por tabagismo. Os dados mostram que o número de casos de hipertensão causada por tabagismo é muito inferior ao número de casos de hipertensão não causada por tabagismo. 
Figura 6 Número de casos de hipertensão no estado do Amapá no período de 2006 a 2012 por tabagismo.

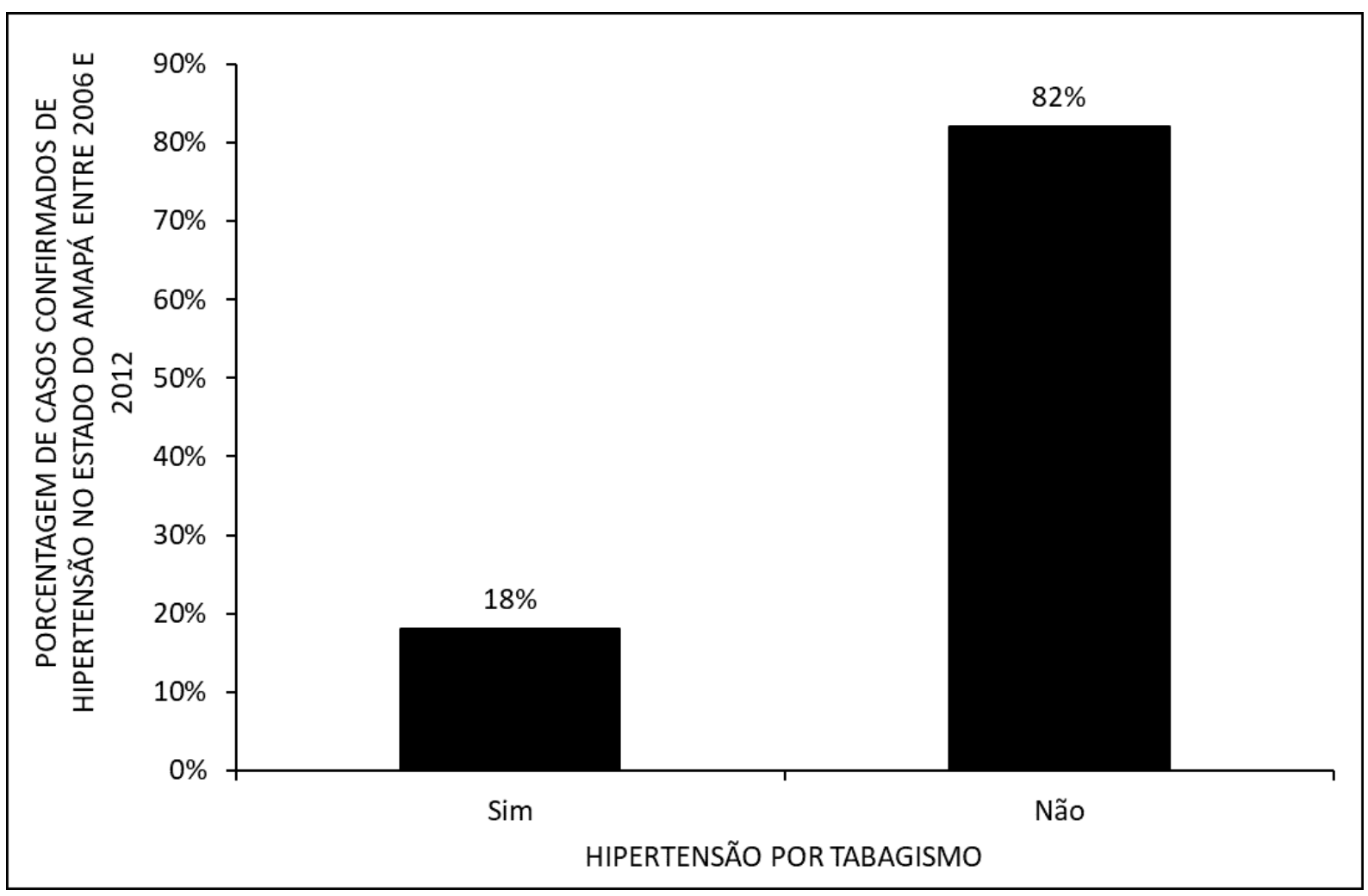

A figura 7 mostra o número de casos de hipertensão no estado do Amapá no período de 2006 a 2012 por região metropolitana. Os dados mostram que o número de casos na capital é maior que o número de casos nos interiores do estado. 
Figura 7 Número de casos de hipertensão no estado do Amapá no período de 2006 a 2012 por região metropolitana.

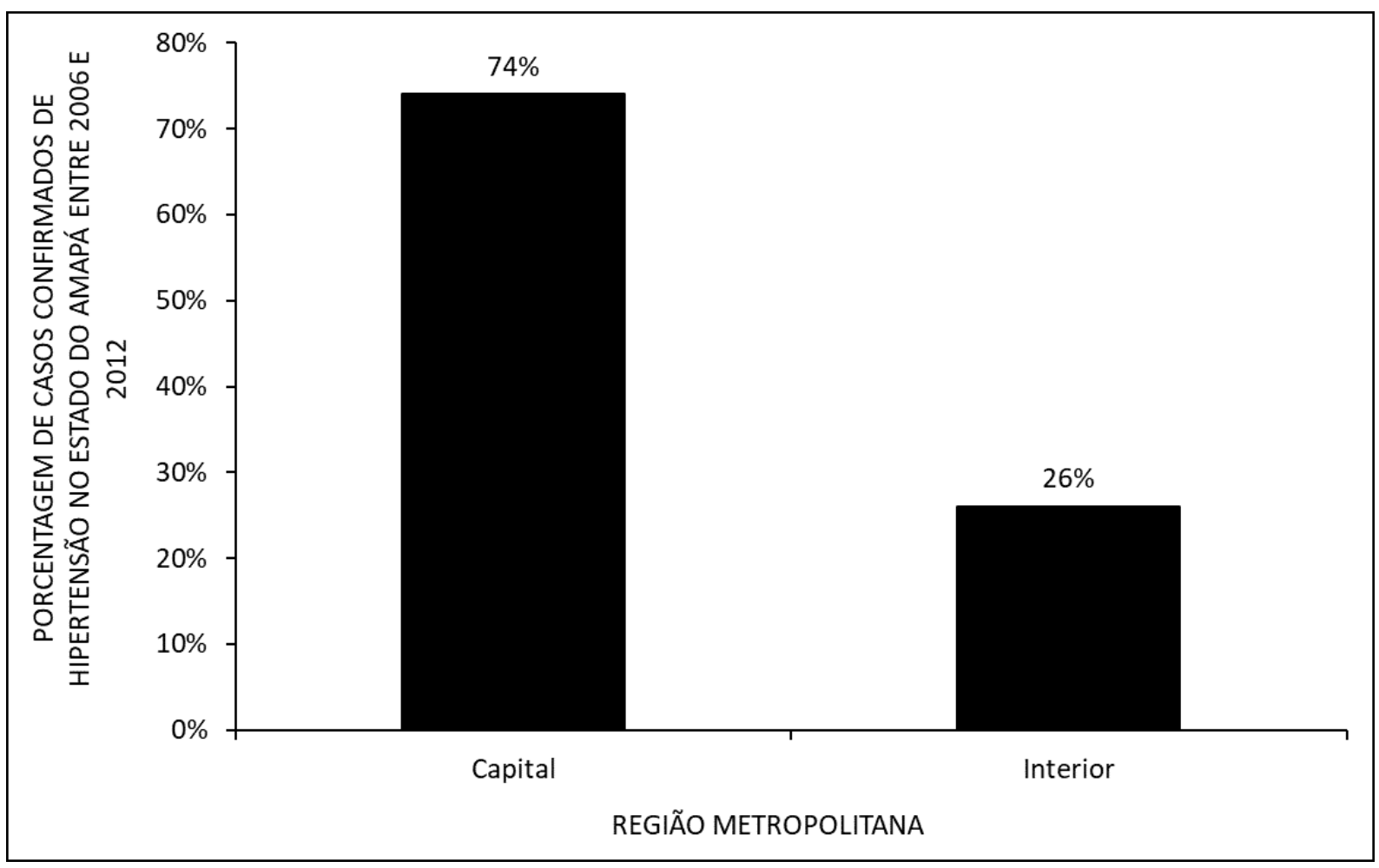

\section{DISCUSSÃO}

A figura 1 mostra a oscilação de casos de hipertensão no Amapá. O número oscilatório de casos de hipertensão pode ocorrer devido às pessoas não aderirem o tratamento de forma correta ou não saberem o real perigo de uma doença crônica igual à hipertensão. Muitos abandonam o tratamento por já acharem que estão curados e depois voltam ao sistema por passarem mal ou então desconsideram os sintomas e acabam não entrando para os registros (Contiero et al., 2009). A maior queda em 2012 se dá pela campanha "Saúde Não Tem Preço", lançada em 2011 pelo governo brasileiro para distribuir gratuitamente medicamentos para hipertensão, diabetes e asma (Brasil, 2015).

Os dados do Amapá condizem com a literatura. O número de casos de hipertensão é maior em mulheres (figura 2), provavelmente devido a maior preocupação delas com a saúde. Geralmente elas são mais sensíveis a sintomas e normalmente procuram 
mais por unidades de saúde e mantém o tratamento. Uma das barreiras para o controle da hipertensão no Brasil é a descontinuidade e a não adesão do tratamento pelos pacientes (Santos, 2011; Nogueira et al., 2010).

No Amapá o número de casos em pessoas na faixa dos 50 anos até os 69 anos é maior que o número de casos nas demais idades (figura 3). O número de casos de hipertensão em pessoas na faixa dos 50 a 69 anos é maior provavelmente devido ao aumento da estimativa de vida e da população de idosos no Brasil. O aumento da idade aumenta o risco de desenvolvimento de doenças crônicas não transmissíveis (Mendes et al., 2014).

Os dados mostram que os casos de hipertensão causados por sobrepeso (figura 4) e de hipertensão causados por sedentarismo (figura 5) são menores que os casos de hipertensão não causados por esses dois fatores. No Amapá, a hipertensão tem como causa principal a genética, quando um indivíduo herda de um dos pais uma combinação de genes com predisposição a elevação de PA e o estresse. Pelo nível escolaridade ser baixo no estado as pessoas acabam não sendo tão qualificadas e sem emprego fixo acabam sendo admitidas em empregos informais onde a carga horaria é grande e há possibilidade de demissão a qualquer momento. A ansiedade e o descontentamento gerados por estes motivos pode ocasionar aumento de estresse nesses indivíduos acarretando a hipertensão (Chagas e Almeida, 2016; Fermino et al., 2009).

Os dados apontam um menor número de casos de hipertensão relacionados a tabagismo no Amapá (figura 6). O tabagismo é um fator de risco que corresponde a $18 \%$ dos casos de hipertensão no Amapá. Esse fator é relativamente baixo se comparado aos outros, pois o governo brasileiro, desde a década de 90, vem promovendo campanhas para redução do consumo do cigarro. O reflexo dessa campanha pode ser a diminuição dos casos de pressão alta ligada ao tabagismo (Duncan et al., 2012).

O número de casos na capital é maior que o número de casos nos interiores do estado (figura 7). O maior número de casos de hipertensão arterial se encontra na capital do 
estado devido provavelmente facilidade de acesso a unidades de saúde. A dificuldade acesso inviabiliza o tratamento não somente dos pacientes hipertensos como também para pacientes de outras doenças (Brasil et al., 2015).

\section{CONCLUSÃO}

No Amapá casos de hipertensão persistem pela falta de aderência ao tratamento ou ao tratamento incorreto, ocasionado pela falta de informação sobre a gravidade da pressão alterada para a saúde. Mulheres apresentam maior cuidado pessoal com a saúde e maior manutenção do tratamento após o diagnóstico. Doenças crônicas não transmissíveis oferecem maior risco à população com maior faixa etária. A causa efetiva dos casos de hipertensão no Amapá parecem ser o fator genético e o estresse, suplantando fatores como sobrepeso e sedentarismo. A escolaridade reduzida leva a insegurança no trabalho, aumentando o estresse e alterando a pressão sanguínea. $O$ tabagismo não se apresenta como fator principal pois sua redução nacional foi alcançada com campanhas educacionais de jovens. Infelizmente, casos de dificuldade de acesso a saúde, diagnóstico e tratamento de pacientes hipertensos permanecem reais no interior do estado.

\section{REFERÊNCIAS}

ANDRADE, S.S.A.; STOPA, S.R.; BRITO, A.S.; CHUERI, P.S.; SZWARCWALD, C.L.; MALTA, D.C. Prevalência de hipertensão arterial autorreferida na população brasileira: análise da Pesquisa Nacional de Saúde, 2013. Epidemiol. Serv. Saúde, Brasília, v. 24, n.2, 297-304, 2015.

BRASIL. Hipertensão atinge mais de 30 milhões de pessoas no País. Disponível em: <http://www.brasil.gov.br/saude/2015/04/hipertensao-atinge-mais-de-30-milhoes-depessoas-no-pais> Acesso em: 21 de Setembro de 2017.

CONTIERO, A. P.; POZATI, M. P. S.; CHALLOUTS, R. I.; CARREIRA, L.; MARCON, S. S. Idoso com hipertensão arterial: dificuldades de acompanhamento na Estratégia Saúde da Família. Rev Gaúcha Enferm., V. 30,N. 1, 62-70, 2009. 
CHAGAS, J. A. S.; ALMEIDA, A. N. F. Caracterização epidemiológica de pacientes hipertensos usuários de uma unidade básica de saúde da região Norte. Estação Científica (UNIFAP) Macapá, v. 6, n. 2, p. 105-116, maio/ago. 2016.

DUNCAN, B.B.; CHOR, D.; AQUINO, E. M. L.; BENSENOR, I. M; MILL, J. G.; SCHMIDT, M. I.; LOTUFO, P. A.; VIGO, A.; BARRETO, S. M. Doenças crônicas não Transmissíveis no Brasil: Prioridade para enfrentamento e investigação. Rev. Saúde Pública, v. 46, 126-34 2012.

FERMINO, R. C.; SEABRA, A.; GARGANTA, R.; MAIA, J. A. R. Fatores genéticos e variabilidade na pressão arterial. Uma breve revisão da literatura. Rev Bras Cineantropom Desempenho Hum, v.11, n.3, 341-349, 2009.

FONSECA, F.C.A.; COELHO, R.Z.; NICOLATO, R.; MALLOY-DINZ, L.F.; FILHO, H.C.S. A influência de fatores emocionais sobre a hipertensão arterial. J Bras Psiquiatr., v. 58, n.2, 128-134, 2009.

MENDES, G. S.; MORAES, C. F.; GOMES, L. Prevalência de hipertensão arterial sistêmica em idosos no Brasil entre 2006 e 2010. Rev. Bras Med. Fam. Comunidade, v. 9, n. 32, 273-278, 2014.

MICHELI, T.; BITARELLO, D.A. O enfermeiro, na atenção básica, ao lidar com hipertensão como fator de risco para insuficiência renal crônica. Revista de Iniciação Científica da FFC, v. 8, n.3, 329-337, 2008.

MONTEIRO, P.C.; SANTOS, F.S.; FORNAZARI, P.A.; CESARINO, C.B. Características biossociais, hábitos de vida e controle da pressão arterial dos pacientes em um programa de hipertensão. Arq. Ciênc. Saúde, v.12, n.2, 73-9, 2005

NOGUEIRA D.; FAERSTEIN E.; COELI C. M.; CHOR D.; LOPES C. S.; WERNECK G. L. Reconhecimento, tratamento e controle da hipertensão arterial: Estudo PróSaúde, Brasil. Rev. Panam Salud Publica, v. 27, n. 2,103-9, 2010. 
SANTOS, Z. M. S. A. Hipertensão arterial - Um problema de saúde pública. Rev. Bras Promoç Saúde, v. 24, n. 4, 285-286, 2011.

ZAITUNE, M.P.A.; BARROS, M.B.A.; CÉZAR, C.L.G.; GARANDINA, L.; GOLDBAUM, M. Hipertensão arterial em idosos: prevalência, fatores associados e práticas de controle no Município de Campinas, São Paulo, Brasil. Cad. Saúde Pública, Rio de Janeiro, v.22, n.2, 285-294, 2006.

Enviado: Abril, 2020.

Aprovado: Abril, 2020. 